\title{
BIENES MUEBLES DE MUDÉJARES CASTELLONENSES. SIGLO XV
}

\author{
Joaquín Aparici Marti *
}

\section{LAS ACTAS DEL JUSTICIA COMO FUENTE DE ESTUDIO}

El tema de los inventarios de bienes mudéjares y moriscos no es una novedad. Sobre el asunto ya se han realizado trabajos con ámbitos geográficos tan distintos como Andalucía, Teruel, Valencia e incluso la zona de Castellón. Al respecto, los estudios sobre los moriscos andaluces son cuantitativamente los más numerosos, basados muchos de ellos en cartas de dote y arras del siglo XVI. A nivel turolense, valenciano o castellonense, el número de publicaciones es sensiblemente menor, si bien volvemos a observar que se refieren, mayoritariamente, al período morisco. En algunos de estos trabajos se transcribe el listado de bienes y se procede al análisis global de los mismos. En otros se toma en consideración sólo parte de esos bienes para realizar un interesante estudio lingüístico o etimológico, especialmente de la indumentaria y las joyas ${ }^{1}$.

* Universitat de València. Departamento de Historia Medieval.

1. Muchos de esos trabajos se basan en cartas de dote y arras, y realizan como ya hemos mencionado listados de palabras para conocer su origen y significado, especialmente respecto a vestidos y joyas. Véase M.J. Osorio Pérez, «Aproximación al status socio-económico de la mujer morisca a través de los protocolos granadinos: fuentes para su estudio», IV Simposium Internacional de Mudejarismo, 1993, pp. 667-675. J. ALBARRACín NAVARRO, «Una carta morisca de dote y arras. Granada (1540) y Juan Martínez Ruiz», Sharq al Andalus, 12, 1995, pp. 263-276. Id., «Nueve cartas moriscas de dote y arras de Vera (Almería, 1548-1551)», Actas del Congreso La Frontera Oriental Nazarí como sujeto histórico (ss. XIII-XVI), 1997, pp. 513-530. C.A. MARTínEZ ALBARRACÍN, «Léxico de algunas ropas y joyas de una carta de dote y arras de una morisca granadina del siglo XVI (24-I-1563)», VII Simposio Internacional de Mudejarismo, 1999, pp. 679-689. L.R. MENÉNDEZ DE LuARCA, «De cómo vivían los moriscos en sus casas», VIII Simposium Internacional de Mudejarismo, vol. II, 2002, pp. 765-769, donde realiza un breve recorrido por las costumbres moriscas vistas desde la óptica cristiana, transcribiendo los bienes de una carta de dote y arras fechada en 1568, y que extracta de otra obra, J. MARTINEZ RUIZ, «Siete cartas de dote y arras del Archivo de la Alhambra (1546-1608)», Revista de dialectología y tradiciones populares, 22, 1966, pp. 54-59. M. ARCAS CAMPOY, «Inventario de bienes de una morisca granadina emigrada a Lorca (Murcia)», Al-Masaq, 4, 1991, pp. 35-49. A nivel turolense existe un reciente trabajo sobre los mudéjares de estas tierras en el que se publican hasta seis inventarios de mudéjares de Albarracín que, a fin de no convertirse al cristianismo, se fugaron de la población en 1504, quedando sus pertenencias consignadas por el alguacil de la Inquisición Francisco de Robres (morisco que había sido alfaquí de Albarracín) para hacer frente a una deuda de 
Las fuentes para el estudio de la minoría islámica en nuestras tierras son variadas y, afortunadamente, se conservan importantes series documentales de las que extraer las noticias. En una de las últimas publicaciones del Centro de Estudios Mudéjares (año 2005) reconocidos investigadores participaron con el objetivo de configurar un libro que sirviera como base de futuros trabajos: Fuentes documentales para el estudio de los mudéjares. Allí se tomaba nota de la importancia de la documentación sobre mudéjares contenida en el Archivo de la Corona de Aragón, en los archivos nobiliarios como el de la casa Ducal de Medinaceli, los archivos notariales, y los archivos municipales (centrándose en el de Borja), haciendo mención explícita a los tipos de registro donde buscar, y también a aquellos que ofrecían posibilidades de encontrar referencias ${ }^{2}$.

Ahora, personalmente, trataré de acercarme a la realidad material de la vida diaria de los mudéjares castellonenses (y en menor medida de los moriscos) a través de los inventarios de bienes muebles realizados por orden de un cargo público, como es el justicia, y consignados en los libros y documentos emanados desde la escribanía de esta institución.

En los libros de Cort del Justícia localizados para Castellón, Segorbe y $\mathrm{Onda}^{3}$, que han sido la base de esta pequeña aportación, encontramos la misma estructura interna, ordenación de los textos y contenido informativo, aspecto que nos habla a su vez de las actuaciones y competencias del propio cargo judicial. De forma breve, estos libros contienen cuatro o cinco grandes apartados, a saber el libro de Obligacions-Condempnacions, el de Actes Comuns, el de Lletres, y en ocasiones se conserva el de Subhastes. Otros apartados, como el de Clams, Pena del Quart, etc., aparecen generalmente en menor número, y en muchas ocasiones insertos dentro de los anteriormente mencionados. A su vez, dentro de cada

12.000 ss. que acreditaba el caballero Pedro Navarro. Véase G. NAVARro y C. VillanueVA, Los mudéjares de Teruel y Albarracín. Familia, trabajo y riqueza en la Edad Media, 2003, pp. 191-197. Para el caso de la zona de Castellón, véase el trabajo de M. ROSAS ARTOLA, «Notes sobre la vida domèstica d'una família de moriscos de Borriol a través d'un inventari de 1551», V Jornades culturals a la Plana de l'Arc, 2003, pp. 45-56. El morisco de Borriol en cuestión era Pere Faraig, alias Carreres, transcribiéndose el inventario de bienes tras su óbito. Para el caso valenciano en general véase C. BARCELÓ, Minorías islámicas en el P. Valenciano. Historia y dialecto, 1984, pp. 105-107, donde publica tres inventarios de bienes mudéjares o moriscos, a saber de Çat Alcatxon (1351, Alfarb), Abdallá Torralbí alias Sardina (junio de 1497, Valencia), y Miquel Gàlip (1585, Benifairó de Valldigna). Véase también C. BARCELÓ y A. LABARTA, «Indumentaria morisca valenciana», Sharq al-Andalus, 2, 1985, pp. 49-73.

2. Los autores que participan en la obra son M.T. Ferrer i Mallol, I. Montes Romero-Camacho, G. Navarro Espinach y J.F. Egea Gilaberte. El Centro de Estudios Mudéjares depende del Instituto de Estudios Turolenses. Además de los libros monográficos de la serie de Estudios Mudéjares, el centro organiza y publica las actas de los diferentes Simposia Internacionales de Mudejarismo que se celebran en Teruel cada tres años.

3. Para el caso de Castellón, hemos utilizado los libros del justicia contenidos en el Archivo Histórico Municipal (AHMCs). En el de Onda, los registros del justicia existentes en la sección del Baile General del Archivo del Reino de Valencia (ARV), y para el caso de Segorbe, los registros del justicia del Archivo Municipal (AMS), a los que hemos unido los protocolos del Archivo de la Catedral (ACS). 
uno de esos grandes apartados se puede encontrar una gran variedad de registros informativos ${ }^{4}$. La utilización de esos registros permite un amplio abanico de posibilidades y temas a tratar, que pueden ir desde aquellos de tipo económico (obligación por compra-venta de productos, préstamos, reconocimiento de deudas), geográfico (origen de las personas que intervienen, itinerarios y áreas de influencia), delictivo (agresiones, asesinatos, treguas, calumnias), etc. ${ }^{5}$, o como en nuestro caso, de aproximación a la realidad material del interior de las casas mudéjares a través de la scripció de bens por deudas no satisfechas.

Con respecto al tema que ahora me interesa, los inventarios de bienes, es cierto que la aproximación sólo puede ser parcial pues la relación de útiles que se consigna en las actas judiciales no tiene la misma intención como si se tratase de un acto notarial. En estos últimos, el notario tiene cuidado de anotar puntualmente todos y cada uno de los bienes que se poseen, generalmente por tratarse de un inventario post mórtem (véase el documento n. ${ }^{\circ} 19$ ), inventario al que en ocasiones acompaña una posterior almoneda o subasta de bienes, que nos permite incluso conocer el precio o valor de tasación de dichos útiles. Sin embargo, mientras para la zona de Segorbe sí se conserva un buen número de protocolos o notales, para el área de la Plana de Castellón no se conserva documentación notarial del período medieval, existiendo sólo un reducido número de éstos a partir de las primeras décadas del XVI ${ }^{6}$.

Por ello los actos ante el justicia cobran importancia especial. A instancia de la parte demandante, ante el justicia se realiza el inventario de bienes de un individuo hasta que el listado de los mismos equivale al montante global de la deuda, momento en que se acaba el inventario. Resulta pues algo parcial, condicionado al valor de lo adeudado, por lo que no son inscritos la totalidad de los bienes. Incluso en ocasiones ni siquiera se llega a anotar dichos bienes, quedan-

4. Así, por ejemplo, en los libros de obligaciones encontramos los nombres, apellidos, alias, oficio o cargo, procedencia, identificación étnico-religiosa, etc., de las partes. El sujeto activo acepta el objeto de la obligación, que viene estipulado en el pago de cierta cantidad de dinero, mercancía, etc., dentro de un plazo temporal determinado. Esa obligación nace por una relación contractual de préstamo, compra-venta, o servicios, que garantiza el sujeto pasivo al confesarse deudor del sujeto activo, sometiéndose a la pena del quart, y obligando sus bienes. En los libros de Actos Comunes aparecen por ejemplo todas las treguas establecidas, todas las referencias a delitos (agresión, robo), los juramentos de los corredores, procesos judiciales donde declaran las partes y los testigos, etc.

5. Por ejemplo, la utilización exclusiva de los libros de justicia han servido para el estudio de las actividades económicas de los judíos castellonenses. Véase J.R. MAGDALENA, Judíos y cristianos ante la Cort del Justícia de Castellón, 1988, Dip. Castelló. A.J. MIRA JóDAR, «Els diners dels jueus. Activitats econòmiques d'una família hebrea al món rural valencià», Revista d'Història Medieval, 4, 1993, pp. 101-126. También han servido para aproximarse al mundo mudéjar a través de ciertos conflictos, como C. DíAz, «La justicia cristiana ante los mudéjares: los Bocayo, una familia valenciana del siglo XV», B.S.C.C., 69, 1993, pp. 201-209. O a un análisis más global de las posibilidades económicas de los mudéjares, en J. APARICI MARTí, «Conexiones comerciales de corto radio entre Onda y las morerías cercanas en el transcurso del s. XV», Butlletí d'Estudis Municipal, 1, 1999, pp. 107-126.

6. Su utilización para el estudio de los bienes moriscos en M. Rosas ArTOLA, op. cit., pp. 45-56. 
do en los libros-registro sólo la intitulación de aquello que se iba a hacer ${ }^{7}$. Además, generalmente no se realiza, como en los actos notariales, un recorrido visual por el espacio habitado o la estructura y organización interna de la casa. Por ello estos listados son un tanto limitados. Sin embargo, a falta de otro tipo de registros, éstos son los únicos que nos acercan al interior de la vivienda mudéjar en la zona de Castellón, y a la realidad material de su convivencia diaria ${ }^{8}$.

Además, la utilización de los inventarios de bienes se reafirma como fuente insustituible para el conocimiento de la cultura material bajomedieval de cualquier persona en general, y del grupo mudéjar en particular. Como indicó N. Pounds, el mundo de los objetos bajomedievales son "la imagen más íntima que tenemos de la vida y las posesiones de las gentes" ${ }^{\prime \prime}$. Más aún, hay casos en que documentamos pocos objetos, pero para unas funciones muy claras, invitándonos a hablar de simplicidad. Sin embargo, la escasez de elementos en ocasiones se compensa con su multifuncionalidad (por ejemplo, caixes, banchs, etc., son empleados para depositar otros objetos y, simultáneamente, como muebles o puntos de apoyo). También hay muebles reversibles que permiten el ahorro de espacio, como las mesas o sillas plegables, camas desmontables, etc. Incluso la utilización de estos inventarios sirve para complementar los límites del registro arqueológico. La cerámica, que en la mayor parte de las excavaciones arqueológicas de espacios domésticos puede representar más del 90\% del material recuperado, en algunos inventarios no supera el 18\% de los objetos listados. El porcentaje restante (del orden del $82 \%$ ) no sería documentado arqueológicamente más que en una proporción muy baja y en condiciones de conservación deficientes (madera, metal, vidrio, textil, junco, cuero, etc.), y sin embargo representan la mayor parte del mobiliario que existía en las viviendas de la época ${ }^{10}$.

7. El 18 de junio de 1441, en el libro de subastas se consignó: “a instància de Johan Miró, sabater, subastats com a bens de Mahomat Botori moro de la moreria de Castelló los bens mobles de aquell segons son scrits, qui li diu e et cetera tot hom et cetera...". A continuación "a instància de Jordi Bago procurador d'en Francesch Guerau, subastats com a bens de Abdallà Çalom e de Muge sa muller, ... qui li diu e et cetera tot hom et cetera...". Sin embargo, los bienes no fueron escritos ni listados en dicho libro. Ambos ejemplos en AHMCs, justicia n. ${ }^{\circ}$ 22, libro de subastas. Todos estos datos resultan también muy útiles a nivel de creación de listados prosopográficos de los mudéjares, especialmente de Castellón, pues la morería de esa localidad se constituyó, materialmente, a fines de 1439, por lo que los mudéjares documentados en 1440 y 1441 debieron ser de los primeros en habitarla.

8. A este nivel por ejemplo y para la zona de estudio sólo disponemos de una aproximación parcial referente al mobiliario e indumentaria de los mudéjares castellonenses del siglo XV. Se trata de unos listados simples en los que se enumeran muebles, útiles de cocina, aperos agrarios, ropa de vestir y de cama, especificándose en ítem separado aquellos tildados en la documentación como morisch, pero que en su conjunto no proceden de inventarios listados, sino de obligaciones de compra-venta de un producto ante el justicia. Véase al respecto C. DíAz, Los musulmanes del norte valenciano durante el siglo XV: crédito y endeudamiento, Tesis doctoral inédita, Univ. Jaume I, pp. 248259. Véase también, para el período morisco, el trabajo ya mencionado de M. Rosas Artola.

9. N. Pound, La vida cotidiana. Historia de la cultura material, 1999, p. 246.

10. J.A. EIROA RodrígueZ, «Los inventarios bajomedievales como fuente para el estudio del mobiliario doméstico: una aproximación a los límites del registro arqueológico», Actas del II Simposio de Jóvenes Medievalistas, 2006, pp. 23-36. 
En conjunto, en el presente trabajo hemos realizado la transcripción de 23 inventarios, de extensión desigual, referidos a mudéjares y moriscos de las localidades de Castellón, Onda y Segorbe (todos ellos con morería, pero desigual valor demográfico $)^{11}$. Con la excepción del documento n. ${ }^{\circ} 19$, que es un inventario procedente de un protocolo notarial segorbino, y del n. ${ }^{\circ} 14$, que son los bienes del interior de un cofre robados a un mercader mudéjar, el resto proceden todos de inscripciones judiciales por razón de deudas contraídas y no satisfechas.

\section{TRANSCRIPCIÓN DOCUMENTAL DE LOS INVENTARIOS}

\section{Doc. 1}

1441, febrero, 16. Inscripción de bienes de casa del mudéjar de Castellón Mahomat Mogip a instancia de Johan Giner. En fecha 7 de marzo de ese año Çahet Tordello, de Castellón, caplevó todos los bienes muebles inventariados de Mogip por valor de 3 florines y medio (AHMCs, justicia n. ${ }^{\circ} 12$, act. com).

Primo hun pavés,

item hun mantó blau,

item dos broqués,

item una flaçada ab hun lançol.

\section{Doc. 2}

1441, marzo, 3. Inscripción de bienes de casa de Pexcat, mudéjar de Castellón a instancia de Johan Miquel, por valor de 30 ss. (AHMCs, justicia n. ${ }^{\circ} 12$, act. com).

Primo una taula ab sos petges,

item una talequa,

item un lit ab son matalaffe un parell de lançols,

item un rocíblanch.

\section{Doc. 3}

1441, abril, 7. Inscripción de bienes de la casa alquilada en Castellón por el mudéjar albardero, Alí Marclaní, instando Pere Castell, a quien fueron encomendados los bienes (AHMCs, justicia n. ${ }^{\circ} 12$, act. com).

Primo tres agules de fer albardes,

item hun cabacet ab unes stisores e una agulla spardenyera e una macela,

item unes gerres ab figues,

item hun dader trencat.

11. Véase J. APARICI MARTÍ, «Moreries urbanes a Castelló: la integració del treball artesà musulmà durant el segle XV», XVII Congrés d'Història de la C. d'Aragó, 2003, vol. I, pp. 171-184. 


\section{Doc. 4}

1441, junio, 1. Inscripción de bienes de la casa de Abdallà Calom, mudéjar de Castellón, a instancia de Francesc Guerau. Pexcat y Macià, moros, caplevan bienes de casa de Abdallà por valor de 7 libras y media (AHMCs, justicia n. ${ }^{\circ} 12$, act. com).

Primo hun lit ab ses posts,

item una màrfega,

item hun matalaff,

item una flaçada,

e huna mulla de pel negre.

\section{Doc. 5}

1442, abril, 17. Relación de bienes del mudéjar castellonense Jucef Gallego que estaban en poder del judío Samuel Azarilla ${ }^{12}$, y que han sido requisados por Bernat Johan a instancia del vecino de Valencia Pere Pomar (AHMCs, justicia n. ${ }^{\circ} 12$, act. com).

Primo, en la entrada de la casa:

un cub de VIII gerres ab son follador,

item tres gerres bladeres,

item una gerreta ayguadera,

item un manil burell e groch,

item una tauleta de mengar,

item una cadira,

item una gerreta,

item una anab (i) d'argent,

item quatre gerres buydes,

item dues gerres plenes de vi de XXX,

item una caldera gran,

item una pila de fust,

item hun lit de posts ab sa màrfega,

item hun parell de lançols de tres teles de terme,

item una flaçada burella ab listes blanques,

item un banch de cab,

item una (...) de lana filada,

item un matalaff blanch e vermell,

item un caffís buyt,

item una caixa nova de pi,

item una caxa gran de tenir libres,

item un artibanch.

12. Publicado por J.R. Magdalena, op. cit., documento n. ${ }^{\circ}$ 35, p. 199. 


\section{Doc. 6}

1445, febrero, 9. Inscripción de bienes de dos mudéjares. A instancia de Berenguer Castell, vecino de Castellón se hace inventario de bienes de Hamet Alger, de Castellón, bastantes a satisfacer la deuda de 66 ss. (AHMCs, justicia n. ${ }^{\circ} 13$, act. com. f. 78r).

Primo, XX fexos de lii poc mes o menys no piquat,

item hun lit de post ab màrfega e matalaf,

item un parell de igaensties?.

A continuación, a instancia de Castell, se procede al inventario de bienes de Çuleymen Alger, que satisfagan otra deuda de 66 ss.

Primo un lit de posts ab una màrfega e un matalf e hun parell de llançols de li, item una caxa chiqua,

item XXXX fexos de lii no piquat.

\section{Doc. 7}

1445, febrero, 24. Inscripción de bienes del mudéjar de Castellón Abdallà Fellení, instando Berenguer Castell por 22 ss. adeudados (AHMCs, justicia n. ${ }^{\circ} 13$, act. com. f. 82r).

Primo una aljuba verda,

item un aradre,

item un lit ab son matalaff blau.

La dita aljuba fonch donada per la muller del dit deutor e fonch presa per Gilabert, saig, que la porta ab sí.

\section{Doc. 8}

1445, noviembre, 28. Inscripción de bienes de Çuleymen Alger alias Marrano, mudéjar de Castellón, a instancia del castellonense Pere Miró, por razón de deuda de 5 florines (AHMCs, justicia n. ${ }^{\circ}$ 13, act. com. f. 96v).

Primo una caxa ab un matalafet chich,

item hun lit de posts ab sa màrfega, flaçada, travesser e llançol,

item una caxa e dos fexos de lii,

item dotze fexos de lii picat.

\section{Doc. 9}

1445, diciembre, 11. Inscripción de bienes del mudéjar de Castellón Hamet Alger alias Marrano, instando Pere Mut por razón de deuda de 17 ss. (AHMCs, justicia n. ${ }^{\circ} 13$, act. com. f. 97r). Primo un lit ab un llançol, matalaffet e un munt de fexos de lii amerat e picat. 


\section{Doc. 10}

1447, abril, 12. Inscripción de bienes de casa de Façan Xep, mudéjar de Castellón, a instancia de Miquel Arrufat. Los bienes serán caplevats por valor de 22 florines por Johan Miró, mercader, y Berthomeu Agramunt, ambos de Castellón (AHMCs, justicia n. ${ }^{\circ} 14$, act. com).

Primo hun mul ab sa albarda,

item tres relles,

item una caldera,

item hun lit de posts ab son matalaf,

item altre lit ab sa màrfega e matalafet,

item hun parell de lançols,

item hun cubertor blau e vermell,

item hun parel de lançols,

item una flaçada listada,

item tres matalafs de lit,

item hun travesser de lana antich,

item hun cubertor de lit vermell e blau, un matalaff de cavalcor,

item una aljubeta verda chica,

item un gonell negre,

item una aljuba vermella de dona,

item tres aljubes de li,

item hun ¿bode? morat e altre negre,

item dos roves d'oli,

item una toca,

item cinch vels xics de mora,

item dos lançols mongills obrats de seda,

item dos tovalloles grans de seda grans ab listes vermelles,

item una aljuba blanca ab listes vermelles de seda,

item dos draps de cap ab listes de seda,

item hun drap de travesser obrat de seda,

item una caxa e una caldereta.

\section{Doc. 11}

1456, septiembre, 11. Inscripción de bienes encontrados en la casa alquilada en Castellón por Abdallà y la mujer de un tal Pancheta, en valor de una deuda de 24 ss. 2 dd. (AHMCs, justicia n. ${ }^{\circ} 15$, act. com).

Primo hun caldero sotil,

una falç,

una corda de cànem plana,

item una caxeta chiqueta sotil sens cuberta,

item hun capel de sol sotil,

item un passador,

item una ampoleta,

item una carabaça, 
dos scudels grans e una chiqua,

item un cànter,

item hun terracet,

item dos oles,

item un matalafaç dolent desfet,

item un cresol de fere,

item una goça blanqua.

\section{Doc. 12}

1460, febrero, 28. Inscripción de bienes de casa de Çaat Alexep, tejedor mudéjar de Segorbe, estimándose el valor de los mismos en 30 ss. (AMS, justicia, asig. n. ${ }^{\circ} 125$, f. 14v).

Primo sis greals,

item dos almaraxes e dos anstoles de vidre,

item una marfegueta morischa sotil,

item un matalaf morisch sotil blau ab la botana pintada,

item un parell de lançolets d'estopa,

item una manta de vestir,

hun capell vell,

una capa burella,

item dos caxes velles,

item una bargella,

item un garbell,

hun cedàs,

una tauleta morischa.

\section{Doc. 13}

1467, junio, 4. Inscripción de bienes de casa de Alí Marco, de Castellón, a instancia de Guillem Mut, yerno de Bonanat Johan, por valor de 15 libras. Serán caplevats por Mofferriz Bocayó, mudéjar de Cirat. Testigos del acto son Çahat Quimil y Mafomat Jabar (AHMCs, justicia n. ${ }^{\circ} 16$, act. com).

Primo tres flaçades noves,

item hun lit ab posts, peus, màrfega, matalaf e traveser,

item dos gerres bladeres buydes,

item hun pes de ferro,

item una ballesta d'acer,

item una tauleta redona,

item una cadireta plegadiça,

item hun altre lit, posts, peus, màrfega, traveser, matalaf, dos lançols,

item dos camises de mora,

item dos robes roig,

item una gonella de mora vermella e hun mantó morat de moro. 


\section{Doc. 14}

1473, marzo, 6. Ante Johan Colomer, lugarteneniente de Dalmau de Loriz, comendador de Onda, y de Jaume Martí, justicia por la orden de Montesa, comparece Çat Çuleymen alias Moliner, mercader de Toga, exponiendo que hace tres días, reposando en el hostal de Alexi Agustí, sito en Onda, de noche, le robaron un cofre, dentro del cual había lo abajo indicado (ARV, n. ${ }^{\circ} 1314$, justicia de Onda, mano común, f. 137v).

Dues capces de la sua mercaderia, tanquades ab cadenats e ab claus e meses en la una part de la entrada del hostal, la qual la dita hostalera li havia designat... e que en la nit les dites caxes eren stades ubertes, e rompudes los cadenats o tanquadures, e la una de les caxes era stada trobada uberta al entrat de l'estable e levades de aquella:

clochetes de seda obrades e per obrar d'or de bací tenades e blanques,

tres bonets cenats e dos dobles vermells,

un pairer de pintes no sab quantes,

quatre onzes de safrà,

una grosa de tiretes d'anynes,

un ligar de fil de seda,

un ligar ço és cap e coll de seda,

dos voladós de seda crua,

tres clochetes de lenç,

un garlopet obrat d'or de Bechí e cent reals de or en un saquet de cuyro de cabrit,

un pes e un manch

e hun cent de agulles stameneres.

\section{Doc. 15}

1473, mayo, 19. Carta instada por Pero Tomás, vecino de Jérica, contra Çat Fello, mudéjar de Onda, para que se subasten bienes por valor de 240 ss. debidos del precio de una mula. Si no hay bastantes bienes, que se subasten los de su fiador, Guillem Castelló (ARV, bailía general n. ${ }^{\circ} 1314$, f. 69r).

Primo una mula,

una taula de menjar ab sos peus,

un banch,

una flaçada burella,

una gerra bladera,

un llit de posts, peges, màrfega,

una flaçada de listes blanques e blaves,

un cofre,

dues peces de stopa,

tres petges,

màrfega e matalaff. 


\section{Doc. 16}

1488, junio, 7. Inscripción de bienes de Azmet Bocayó, moro de la moreria de la present vila de Castelló, a instancia de Jaume Campos, pelaire. Los bienes foren acomanats ab sagrament a Axa Galbes, viuda mora la qual jura a la alquibla de Mahomet segons en sa ley és acostumat jurar, valorándose los bienes en $40 \mathrm{ss}$. (AHMCs, procesos de corte de justicia n. ${ }^{\circ} 1$, act. com).

Primo en la cambra en la entrada de la casa de aquell:

hun lit ab quatre posts ab sos petges e màrfegua morischa,

item mes hun matalaff mig usat,

item mes altre lit ab hun canyiz e dos cabirons per petges ficats en la paret,

item mes hun banch davant lo dit lit ab quatre peus,

item mes hun lançol de dos teles sobre lo lit,

item en la altra cambra hun lit ab cinch posts e màrfega e petges,

item una serra de una ma,

item una pastera mig usada.

\section{Doc. 17}

1493, septiembre, 28. Inscripción de bienes de casa de Abdulaziz Xacara, mudéjar de Segorbe (AMS, asignaciones justicia n. ${ }^{\circ} 128$, f. 74 r).

En la entrada, primo set faixos de lli ben cuyt per piquar,

item altra part tres feixos de lli cuyt per piquar,

item X gallines e II gualls.

En lo menjador una taula de menjar,

item una garreta.

En la cambra un llençol,

item una caravachina,

item hun cofre buyt pintat ab hun poc de pa,

item una garreta de I cànter mig buyda,

item hun cabaç d'espart ab figues.

En la cuyna, uns ferros,

una paelleta,

item hun teler dolent de texir.

\section{Doc. 18}

1495, septiembre, 22. Inscripción de bienes de casa del mudéjar de Castellón Alí Çalio alias Guordo, a instancia de Anthoni Lançola, por valor de 252 ss. 4 dd. Son caplevats por Bopta Çalio y Abrafim Ferrer, moros de la morería de Castellón (AHMCs, justicia n. ${ }^{\circ}$ 20, act. com).

Primo una mulaça negra,

item una somera,

item una rella,

item tres gerres grans plenes de forment,

item quatre fexos de li piquat. 


\section{Doc. 19}

1499, marzo, 18. Inventario de bienes de casa del difunto Hamet Alfaquinet, mudéjar segorbino (ACS, protocolo n. ${ }^{\circ} 718$, cuadernillo suelto n. ${ }^{\circ} 8$ ).

Primo en la cambra, item en lo lit hun matalaff negre ab pintures morisques de lana, item hun traveser blanch,

item hun parell de lançols de dos teles cascú,

item hun cobertor vell,

item hun lançol de dos teles vell,

item dues lances,

item una cervelera,

item una spasa,

item hun manill pintat,

item hun cofre vell en lo quall foren trobades les coses següents:

item hun canó (i) ab listes als caps la una negra e l'altra vermella,

item huna cara de coxí de diverses colors,

item huna cara de luir ab les listes morades,

item altra cara ab listes morades e negres als caps,

item una cara de matalaff de diverses colors,

item unes tovalles velles,

item una cara als caps ab listes vermelles,

item hun lançoll de dos teles obrat als caps,

item tres cares de coxins morishcs obrades de diverses colors,

item hun lançoll de dos teles obrats los caps de seda,

item una almexia ab listes verdes, vermelles e morades, de seda les listes,

item hun alna de lançoll pintat als caps de seda,

item hun albaden vernoy,

item altre albaden morat,

item hun gramalot vell morat e negre,

item huna camisa de home,

item dues lliures de fill poch mes o menys,

item hun cofrenet chiquet vell en lo quall foren trobats los bens següents:

primo una branqua de corall engastada ab cap de argent,

item sis alferides de argent,

item hun real de argent,

item dos anellets de argent,

item una agulla de argent,

item una domina de argent,

item unes mànegues ab listes de grana,

item altres miges mànegues ab listes morades,

item una alquench vermell als caps de or,

item altre alquench morat,

item hun almaysar vermell ab listes verdes e blaves,

item hun alquinal de fill,

item dos alquinalls de lenç prims ab listonets,

item hun banch, 
item tres camises de dona,

item dins lo dessús dit artibanch foren trobades les coses següents:

primo tres madexetes de cotó la una de blanch e les dues vermelles,

item una cara de matalafet,

item hun bolich ab set madexes de cotó e dues madexes de stopa vermelles e dues blanques,

item dos alquinals blanchs ab listonets negres,

item una manilla de argent,

item dues camises de home dins una canasta,

item una caixa dins la qual foren trobades les coses següents:

item unes cuyraces,

item hun peset ab ses peses,

item unes mànegues de grana,

item una albocaya blanqua ab les vores negres,

item hun alquenall vermell ab los caps de or,

item hun almexemer,

item miges mànegues de llenç ab listes grogues,

item una còfia morisqua ab sa coha del temps antich,

item unes tovalles de un alna,

item hun lançoll chich pintat als caps,

item dues alnes de lenç,

item hun mandill blanch,

item una cara de matalaf chich morisch,

item una caixa ab dotze libres morischs,

item hun cafis de paniz.

Item en una altra cambra foren trobades les coses següents:

primo hun coci chich,

item una gerreta chiqua,

item altra gerreta chiqua,

item hun librell de pastar,

item hun cedàs,

item hun aro ab una poqua farina,

item hun pes de spart,

item hun garbell,

item hun cabàs ab una poqua de dacça,

item hun ceno buyt,

item hun buch ple de stopa.

Item en una altra cambra foren trobats los següents bens: primo en lo lit una màrfega,

item hun matalaf de lana groch,

item una flaçada blanqua ab listes negres e burelles,

item hun parell de lançolls de stopa de dos teles cascun,

item una roda de torn,

item hun librell de pastar,

item hun tornet chiquet,

item hun pavés e una pavetina,

item hun peu de debanadores,

item hun teler de texir lenç.

Item en la cuyna, 
item unes treudes,

item una sarten de ferro,

item una giradora,

item hun asset de ferro,

item hun gancho de ferro,

item tres cresols,

item quatorze scudelles de terra,

item una olla,

item quatre buchs de colmenes,

item deu ligaces de llavor set de dacça e tres de paniz,

item dos fexets de spart,

item dos orons buyts.

Item en lo stable,

item una mula de pell negre,

item set canyinços de fer seda.

Item dues peces en la horta dels moros que són cinch fanecades, afronten ab terra de Afen e ab peça de Carmona e ab Razim Etarongo, item una vinya en lo olivar que són dues fanecades afronten ab vinya de Alí Ruvia e ab la muntanyeta de Càrrica.

Doc. 20

1513, junio, 21. Scripció de bens de la casa de Asmet Alvayet et Mariem sa muller moros vehins de Castelló, a instancia de Miquel Castell y de la señora na Ysabell Escobar. El mudéjar de Castellón Abdolasis Mascor los capleva por valor de 21 ss. (AHMCs, justicia n. ${ }^{\circ}$ 31, act. com).

En la entrada, primo una paella e hun ferro,

item dos escudelles y hun tallador de fust,

item hun capús de pardillo vell.

En la cambra primo una pastera de pastar,

item una taula de sis petges,

item una tauleta de mengar ab una destral,

item una màrfegua plena de palla.

En la cambra de dormir item hun coffre vell ab hun cubertor buyt,

item una cayxa buida,

item hun taulel de pugar al lit,

item hun lit ab sos petges y sa màrfegua,

item hun lançol damunt lo lit.

Doc. 21

1519, agosto, 22. Scripció de bens de la casa de Mahomat Mançor, a instancia de Martí Alberich de Castellón. Los bienes son caplevados por Asmet Faraig moro de la moreria de Castelló. El documento está muy deteriorado (AHMCs, justicia n. ${ }^{\circ} 36$, act. com).

Primo hun macho negre,

item hun altre macho pardo,

item hun ase pardo,

item hun parell de albardes. 


\section{Doc. 22}

1527, julio, 18. Scripció de bens feta en la casa de Anthoni Bocayó, nou convertit. El propio Bocayó y su mujer Joana se hacen cargo de los bienes (AHMCs, justicia n. ${ }^{\circ} 40$, act. com).

Et primo una taula redona,

item hun bres nou ab hun matalafet,

item hun torn de filar seda nou,

item una somera ab una ruqua.

\section{Doc. 23}

1527, julio, 18. Scripció de bens feta en la casa de Yolant Faraga ${ }^{13}$. Son caplevats por el mercader castellonense Hieroni Guiot por un valor de 7 libras (AHMCs, justicia n. ${ }^{\circ} 40$, act. com). Et primo hun lit ab una màrfega, item hun teler de texir ab una tela, item una taula redona, item hun torn de filar seda, item dos gerres miganceres ab dos barcelles de forment poch mes o menys, item hun matalaf rahonable, item hun cofre nou pintat, item hun caxó nou, item una caxeta, item hun matalaf morisch nou, item hun lit ab una màrfega hun matalaf y hun lançol, item una vanova vella blava, item hun brial de cotonina.

\section{ESTUDIO INICIAL}

A través de los inventarios arriba transcritos podemos aproximarnos a la cultura material del grupo mudéjar en tierras de Castellón. Bien es cierto que dichos listados son desiguales en amplitud, pero son con todo muy ricos en matices para escrutar mejor la vida diaria de los miembros de dicha comunidad. Podríamos atender a temas tan diversos como la posesión de armas, la alimentación, los útiles de cocina, las ropas de la casa, etc. Ahora simplemente vamos a detenernos en analizar tres aspectos que resultan muy interesantes para comprender la forma de vida y el trabajo del mudéjar castellonense, a saber: la propiedad de animales de tiro y transporte, el trabajo de las fibras textiles, y los elementos "externos" que los diferencian de los cristianos.

13. Era viuda del mercader mudéjar castellonense Abdulaziz Mascor. Véase P. IRADIEL, D. IGUAL, G. NAVARro y J. APARICI, Oficios artesanales y comercio en Castellón de la Plana (1371-1527), 1995, p. 103. 


\section{ANIMALES DE TIRO Y TRANSPORTE}

La propiedad o disponibilidad de los animales de tiro en manos mudéjares puede observarse básicamente desde dos puntos de vista: el animal como ayuda para las labores del agro, o el animal como medio de transporte o acarreo en manos de los traginers. La propiedad, compra-venta e intercambio de estos animales entre los mudéjares es un hecho constatable en la documentación, especialmente las mulas, mulos y machos.

En los inventarios transcritos, las menciones a animales de tiro son las siguientes:

\begin{tabular}{lc}
\hline TIPOLOGÍA ANIMAL DE TIRO & N. ${ }^{\circ}$ DOC. \\
\hline Un rocíblanch & 2 \\
Una mulla de pel negre & 4 \\
Hun mul ab sa albarda & 10 \\
Una mula & 15 \\
Una mulaça negra, una somera & 18 \\
Una mulla de pell negre & 19 \\
Hun macho negre, item hun altre macho pardo, item hun ase pardo & 21 \\
Una somera ab una ruqua & 22 \\
\hline
\end{tabular}

Respecto a la primera posibilidad, efectivamente algunos de esos animales podían ser utilizados para las labores agrarias, pues en algunos de los inventarios se acompañan con la mención de las rellas (piezas metálicas afiladas fijadas en el arado, que sirven para abrir surcos en la tierra, doc. n. ${ }^{\circ} 10$ y 18), y aradres (doc. n. $^{\circ}$ 7). También es cierto que algunos de los mudéjares reseñados en los inventarios y que declaran la propiedad de animales poseían a su vez parcelas de cultivo, aspecto que puede justificar la dedicación (temporal o no) al trabajo de la tierra. Así por ejemplo, Hamet Alfaquinet de Segorbe (doc. n. ${ }^{\circ}$ 19) disponía de dues peces en la horta dels moros que són cinch fanecades, item una vinya en lo olivar que són dues fanecades; el morisco Anthoni Bocayo (doc. n. ${ }^{\circ} 22$ ) declaraba propiedades inmuebles en la peita de Castellón de los años 1520 y $1527^{14}$; o el mudéjar Pexcat (doc. n. ${ }^{\circ}$ 2), uno de los primeros habitantes de la mo-

14. AHMCs, libro de peita n. ${ }^{\circ} 12$ (año 1520), f. 88v, Parroquia de S. Nicolau. Figura con el nombre mudéjar de Abdulasis Bocayo. Declara una casa en la morería, 15 hanegadas de tierra, 2 hanegadas de moreral con censo de 4 ss., 2 quartons de olivar y medio quartó de higueras. Se estima su valor en poco más de 12 libras y media. Libro de peita n. ${ }^{\circ} 13$ (año 1527), f. 114v, Parroquia 
rería de Castellón que en 1440 pagaba el censo debido de unas tierras, y después se obligaba en el pago del arriendo, a un año, de otra parcela ${ }^{15}$.

Sin embargo, y a pesar de que tradicionalmente se asocia el trabajo mudéjar con las labores del agro, no deja de ser menos cierto que también se les asocia con la profesión de traginers, personas especializadas en el transporte de mercancías no propias, desde un lugar a otro, según el encargo pertinente. Ya lo in-

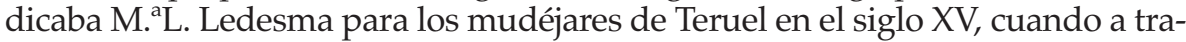
vés del impuesto de las Generalidades se deducía que los transportistas del trigo y fardos de lana desde el sur de Aragón hacia tierras valencianas y castellonenses eran, en su mayoría, mudéjares. También el profesor J. Hinojosa indicaba que en Murcia los mudéjares desempeñaron un papel esencial en el desarrollo del comercio entre las ciudades del reino y en el abastecimiento de la capital al hacer del oficio de transportista casi un monopolio. Incluso en Ávila, en 1488 se afirmaba que todos los recueros son moros, acentuándose durante el siglo XVI esa situación, llegando a dedicarse a ese oficio más del 30\% de los moriscos abulenses ${ }^{16}$.

Ciertamente, en tierras castellonenses los indicios apuntan en la misma dirección. Mencionemos sólo algunos ejemplos. Jahfar, moro d'Uxó, es un personaje muy activo. Documentado entre 1476 y 1503, aparece a primera vista como un traginer al servicio del consejo municipal de Vila-real, cuyo clavario le paga año tras año diversas cantidades por cordes d'espart que portà de València per als pous, en cert port e compra. Pero Jahfar aprovechará ese trasiego hasta la capital del reino para actuar a su vez como factor e intermediario entre los mercaderes italianos afincados en Valencia, distribuidores del pastel colorante, y el artesanado textil de Vila-real. Así, el tintorero de esta última localidad, Pasqual Misansa, pagará a varios mercaderes italianos entre 1478 y 1479 con dinero y con paños acabados a través de nuestro mudéjar ${ }^{17}$.

de S. Nicolau. Figurando ya como Anthoni Bocayo, ha aumentado su valor patrimonial hasta alcanzar algo más de 14 libras peiteras. Además de unas casas declaró la propiedad de 15 hanegadas de tierra, 2 hanegadas de moreral a censo de 4 ss., otras 2 hanegadas de moreral con un censo de 4 ss., 2 quartons de olivar en secano, medio quartó de higueras en el secano y 1 quartó de tierra secano.

15. Pexcat aparece documentado ya en enero de 1440, cuando sabemos que la morería de Castellón se configuró, efectivamente, a fines de 1439. Por ello se trata de uno de sus primeros pobladores. En abril de 1440 fue condenado a abonar un censo debido de 13 ss. 2 dd. a mosén Palau. En julio se obligó ante el justicia a pagar a Yolant, viuda de Bernat Moliner, 33 ss. por el arriendo de un trozo de tierra a un año. La obligación se canceló al año siguiente. Sobre los primeros pobladores de la morería véase A. GARCíA SANZ, «Mudéjares y moriscos en Castellón», B.S.C.C., 28, 1952, pp. 94-114, y J. APARICI MARTí, «Dinámica comercial de la morería de Castelló desde mediados del siglo XV al primer tercio del XVI», Millars, Espai i Història, 17, 1994, pp. 127-144. Los documentos referenciados en AHMCs, justicia n. ${ }^{\circ}$ 12, oblig. (1440, abril, 28 y julio, 13).

16. M. M. Le Ledesma Rubio, Estudios sobre los mudéjares en Aragón, 1996, p. 84. Véase también J. HINOJOSA, Los mudéjares. La voz del Islam en la España Cristiana, 2002, vol. I, pp. 224-225.

17. El caso de Jahfar en J. APARICI MARTí, «Artesanos musulmanes en la Vall d'Uixó a fines del XV e inicios del XVI», en Homenatge a Honori García, 1997, vol. I, pp. 159-170. El contacto con los italianos en D. IGUAL LuIs, Valencia e Italia en el siglo XV. Rutas, mercados y hombres de negocios en el espacio económico del Mediterráneo Occidental, Bancaixa, 1998. 
Otro ejemplo lo documentamos en septiembre de 1495 ante el justicia de Castellón. Ese día comparecieron Azmet Bocayó, de la morería de la villa, y el magnífico García de Sayes. Según parece Sayes, propietario de una canterería y de un rajolar, había logat ací en Castelló a Azmet para que, tornant de València passàs per Paterna perqué allí prengués dos càrregues de obra de terra e que li donaria VII sólidos $V$ dinés. Pero Azmet, ante la imposibilidad física de desviarse del trayecto, subcontrató a un tal Pardo, altre moro, per a que li ajude ab més bésties. Cuando Pardo llegó a Paterna, se le comunicó que la obra de terra ya había salido hacia destino por vía marítima. Pardo regresó a Castellón y pidió que Azmet le pagase los 4 ss. prometidos, respondiendo éste que debería pagarlos Sayes. El justicia acordó enviar a alguien a Paterna para saber de qui és la culpa de la salida de la obra de terra, si de Azmet o de Sayes ${ }^{18}$.

Finalmente, un último ejemplo. En agosto de 1438, Pere Montón, ciudadano de Valencia, actuaba como procurador del mercader italiano residente en la capital del reino, Andrea del Casal, contratando a varios mudéjares de Geldo (a escasos $2 \mathrm{~km}$ de Segorbe) para traer ciertas lanas propiedad de su principal, lanas que estaban en varias localidades de Teruel. Hamet Alget, Huceyt Galebo y Abrafim Razim por pacto especial prometieron llevar dichas lanas con sus bestias hasta Valencia durante el mes de septiembre. Y los lugares de Teruel no estaban, precisamente, cerca del límite fronterizo con el reino de Valencia ${ }^{19}$.

\section{EL TRABAJO DE LAS FIBRAS VEGETALES TEXTILES Y LA SEDA}

Por lo que se refiere al trabajo de las fibras vegetales textiles, lino principalmente, pero también cáñamo y esparto, debemos mencionar que su presencia y cultivo se mantiene a lo largo del siglo XV heredada desde los siglos de dominación islámica, y que tras la conquista cristiana continuó constituyendo un perfil perfectamente caracterizador de las aljamas rurales mudéjares, hasta el mismo momento de la expulsión de 1609.

Tras producirse la conquista cristiana del siglo XIII del Reino de Valencia, los nuevos ordenadores del territorio tramitarán, a través de las cartas de población, las nuevas condiciones de ocupación del terrazgo, que muchas veces eran las mismas que ya satisfacían antaño los mudéjares, pero ahora codificadas las rentas, derechos y obligaciones a favor del nuevo poder. En esas capi-

18. AHMCs, justicia n. ${ }^{\circ}$ 20, act. com (1495, septiembre, 1$)$.

19. Los mudéjares de Geldo prometieron llevar la lana "ab les sues bèsties a costa e messió d'ells, ço és del loch de Aliaga vint saques de lana, de Fenollosa quaranta-dos saques de lana, de Exarch cinquanta-una saques de lana, de les Coves de Exarch vint y set saques de lana, de Mezquita cinquantaquatre saques de lana, Sant del Puerto nou saques de lana... la càrregua no puje de X tro a XI roves pes d'Aragó". Andrea del Casal pagará a razón de 20 ss. por cada carga que traigan. APPV, prot. n. 23903 (1438, agosto, 1). 
tulaciones se consignaban las exacciones sobre los productos del campo, y a menudo se atestiguaba el cobro de diezmos sobre la cosecha del lino, introduciéndose en algunas ocasiones informaciones sobre el mismo trabajo artesanal en el ámbito de la comunidad rural ${ }^{20}$. Estudios puntuales de ámbito comarcal han permitido observar esa dedicación por parte del grupo mudéjar en la zona de Cocentaina, las aljamas del entorno de Onda, o aquellas otras situadas alrededor de Segorbe ${ }^{21}$.

También la producción de seda fue un sector que atrajo el interés mudéjar, no tanto como artesanos cualificados, sino como propietarios de las parcelas donde se plantaban las moreras y como partícipes en las primeras fases de elaboración del producto ${ }^{22}$.

MENCIÓN A LAS FIBRAS TEXTILES, SEDA Y ÚTILES

$X X$ fexos de lii poc mes o menys no piquat, XXXX fexos de lii no piquat

Dos fexos de lii, dotze fexos de lii picat

Un munt de fexos de lii amerat e picat

Hun teler dolent de texir, set faixos de lli ben cuyt per piquar, tres faixos de lli cuyt per piquar

Quatre fexos de li piquat

Una roda de torn, hun tornet chiquet, hun peu de debanadores, hun teler de texir lenç, dos fexets de spart, set canyiços de fer seda

Un torn de filar seda

Un teler de texir ab una tela, un torn de filar seda
N. ${ }^{\circ}$ DOC.

20. D. Igual, J.A. Llibrer y G. NAVArRo, «Materias primas y manufacturas textiles en las aljamas rurales valencianas de la Baja Edad Media», VII Simposio Internacional de Mudejarismo, 1996, pp. 320-321. Basan su cuadro en las cartas pueblas compiladas por E. GuINOT, Cartes de Poblament medievals valencianes, Generalitat, 1991.

21. J.A. Llibrer, Artesanado y formas de organización de la producción textil rural: Cocentaina (14691487), Memoria de licenciatura inédita, Univ. València, 1995. J.A. LlibrER y G. NAVARRO, «Indústria tèxtil del món rural: la Vall d'Albaida i el Comtat a les darreries del segle XV» $\mathrm{Al}$ maig, Estudis i Documents, 8, 1992, pp. 17-23. F.J. CERVANTES, El antiguo patrimonio de María de Luna. Los fundamentos de una empesa feudal, Memoria de licenciatura, Univ. València, 1993, p. 329. J. Aparici Martí, El Alto Palancia como polo de desarrollo económico en el siglo XV. El sector de la manufactura textil, 2001, pp. 65-74. J. APARICI MARTí, «Conexiones comerciales...», 1999, pp. 107126. G. NAVARRO, Industria y artesanado en Valencia, 1450-1525. Las manufacturas de seda, lino, cáñamo y algodón, Tesis doctoral en microficha, Univ. València, 1995.

22. G. NAVARro, El despegue de la industria sedera en la Valencia del siglo XV, Consell Valencià de Cultura, 1992. Del mismo autor, Los orígenes de la sedería valenciana (ss. XV-XVI), Ajuntament de València, 1999. Y también «Estat actual de les investigacions sobre la història de la seda a les comarques castellonenques», VI Congrés d'història i filologia de la Plana, 2001, pp. 177-204. 
Es precisamente a través del sector de la manufactura textil derivada de las fibras vegetales, y de la seda, en los que se puede observar mejor la compaginación e integración del trabajo agrario y el artesano. La dedicación a tiempo parcial resultante de la mengua de las labores del agro en determinados momentos del año facilitaría la realización de dicha labor en el interior de las casas, en una producción de calidad media o baja, de precios asequibles y destinados no sólo al autoconsumo, sino también al mercado local (o en ocasiones regional de corto radio), pero suficiente como para suponer un complemento importante en la economía doméstica del grupo campesino mudéjar. Y ese es un hecho que aparece reflejado en los inventarios de bienes documentados. Además, de entre todos ellos, sólo uno declara como oficio el de tejedor (doc. n. ${ }^{\circ}$ 12) y curiosamente en su inventario no se observan útiles del oficio ni materia prima.

\section{ELEMENTOS “EXTERNOS” DE DIFERENCIACIÓN}

En una sociedad como la valenciana en la Edad Media, donde convivían miembros de las tres religiones del libro, el grupo dominante, el cristiano, intentará crear una serie de mecanismos que le permitan diferenciar "visualmente" y de forma "externa" al "otro", sea judío o musulmán. Ya antes de la conquista de estas tierras, en el IV Concilio de Letrán (1215), se pidió a los reyes cristianos que impusieran a los musulmanes elementos distintivos en los vestidos de éstos, a fin de que pudieran ser facilmente identificados, y evitar así el contacto entre miembros de las diferentes religiones. Parece ser que es en las Costums de Tortosa (1271 / 1277-1279) cuando por primera vez aparece en la Corona de Aragón la obligación de que los mudéjares lleven los cabellos cortados en redondo y la barba larga, debiendo vestir la aljuba o la almexia, y sus mujeres vestir la aldifara ${ }^{23}$. Sin embargo, a lo largo del siglo XIV la situación se relajó y la forma de vestir de cristianos y mudéjares cobró cierta uniformidad, siendo imposible descubrir a qué religión pertenecía un individuo simplemente por su aspecto externo. Por ello, en Valencia, en 1341 el rey Pedro el Ceremonioso prohibió a los mudéjares llevar garceta en el cabello. Sin embargo, la documentación valenciana está plagada de multas por no obedecer esta orden, síntoma inequívoco de que los mudéjares no la cumplían. Por el contrario, y por lo que respecta al vestido, parece ser que o bien fue aceptado por acomodarse a sus tradiciones, o bien cayeron en un cierto desuso las leyes diferenciadoras, aspecto que no es óbice para no pensar en esa diferenciación externa. Así todavía en Valencia en 1373, una ordenanza municipal indicaba que los mudéjares debían llevar la aljuba y una toalla azul en la cabeza, mientras las mujeres cubrían su cara con un velo ${ }^{24}$.

A través de los inventarios se observa en cierta forma esa diferenciación externa. Nosotros no tendremos en cuenta algunos elementos de la indumentaria

23. J. Hinojosa, Los mudéjares..., p. 293.

24. Ibídem, p. 295. M.C. BARCeló, Minorías islámicas..., p. 85. 
como la aljuba, la almexia o el alquinal, por cuanto aunque en origen eran prendas usadas por el grupo mudéjar, su uso se difundió también entre los cristianos ${ }^{25}$, no siendo por tanto un claro elemento diferenciador de carácter "externo" entre ambas comunidades. Sólo hemos contemplado aquellos elementos que iban acompañados del calificativo de moro o morisch, y que hacen alusión no sólo a prendas de vestir sino también a elementos del ropaje doméstico o menaje del hogar.

TIPOLOGÍA CALIFICADA DE MORISCA

Cinc vels xics de mora

Una marfegueta morischa sotil, un matalaf morisch blau ab la botana pintada, una tauleta morischa

Dos camises de mora, una gonella de mora vermella, hun mantó morat de moro Una màrfega morischa

Una caixa ab dotze libres morischs, un matalaff negre ab pintures morisques, tres cares de coxins morischs obrades de diverses colors, una còfia morischa ab sa coha del temps antich, una cara de matalaf chic morisch, un almaysar ${ }^{26}$ vermell $^{2}$

Un matalaff morisch nou
N. ${ }^{\circ} \mathrm{DOC}$.

Para finalizar esta breve aproximación a la vida de los mudéjares castellonenses, hay un hecho que resulta interesante: la mención a una caixa ab dotze libres morischs (doc. n. ${ }^{\circ}$ 19) propiedad de Hamet Alfaquinet de Segorbe (quien curiosamente es también quien posee más prendas tildadas de moriscas), o la de una caxa gran de tenir libres (doc. n. ${ }^{\circ}$ ) propiedad de Jucef Gallego, de Castellón, nos permite vislumbrar la continuidad y / o supervivencia de una cultura propia dentro de la comunidad mudéjar castellonense, posiblemente como complemento del uso público de su propia lengua y de su enseñanza. Precisamente de esos libros moriscos, sin más adjetivación, apenas tenemos noticias sobre su difusión, temas tratados o contenido, pero posiblemente jugaron un papel importante como transmisores de cultura para las generaciones posteriores ${ }^{27}$.

25. M. Astor LANDETE, Valencia en los siglos XIV y XV. Indumentaria e imagen, 1999. Véase las voces correspondientes a aljuba (túnica larga), almexia (variante de la aljuba, con mangas anchas), alquinal (velo y tocado en la cabeza), etc.

26. Según J. AlbARRACín, «Nueve cartas moriscas...», p. 521, el almaysar era una especie de toca que generalmente se llevaba enrollada en la cabeza como un turbante, propia de los moriscos.

27. J. Hinojosa, Los mudéjares..., p. 304, alude al trabajo de M.C. BArCeló, Minorías islámicas..., p. 140, quien documentó a un mudéjar de Alfarb al que en 1348 le robaron un libre morisch que valía 10 ss. O a Jucef, mudéjar castellano, que en 1348 se llevó desde Valencia XX libres morischs. Incluso se menciona a Alí Gebellí, quien entre 1439 y 1445 era moro llibrer de la morería de Valencia. Este mismo mudéjar aparece como Alí Gibili, lligador de llibres, en un listado prosopográfico entre 1440-1451 publicado por M. RUZAFA, «Las actividades industriales de la morería de Valencia», VI Simposio Internacional de Mudejarismo, 1996, p. 280. 


\section{RESUMEN}

Transcripción y estudio de 23 inventarios de bienes muebles de mudéjares castellonenses a través de los libros del Corte de Justicia para Castellón, Segorbe y Onda, fuente de muchos datos de diverso tipo sobre la vida de estos mudéjares y que generalmente se redactan post mortem para satisfacer deudas del fallecido. Se centra el análisis en la propiedad de animales de tiro y transporte, el trabajo de las fibras textiles y los elementos externos que los diferencian de los cristianos.

\section{ABSTRACT}

Transcription and study of 23 inventoires of personal properties of Mudejars from Castellón through the books of the Court of Justice in Castellón, Segorbe and Onda, which are source of so many different data on the lifes of these Mudejars. These texts are generally drafted post mortem to pay debts of the deceased. Analysis focuses on the possession of transport animals, textiles and the external elements that distinguish them from Christians. 